P-C bond oxidation

\title{
Oxidation of a P-C bond under mild conditions
}

\author{
${\text { Gordana Ilić[a], Rakesh Gaguly }{ }^{[a]} \text {, Milena Petković }}^{\star[b]}$ and Dragoslav Vidović ${ }^{\star[a]}$
}

Abstract: The reactivity of phosphenium dication $\left[\left(\mathrm{Ph}_{3} \mathrm{P}\right)_{2} \mathrm{C}-\mathrm{P}-\mathrm{NiPr}_{2}\right]^{2+}, \mathbf{1}^{2+}$, towards pyridine $\mathrm{N}$-oxide (O-py) has been investigated. The resulting oxophosphonium dication $\left[\left(\mathrm{Ph}_{3} \mathrm{P}\right)_{2} \mathrm{C}\left(\mathrm{NiPr}_{2}\right) \mathrm{P}(\mathrm{O})(\mathrm{O}-\mathrm{py})\right]^{2+}, \quad \mathbf{2}^{2+}$, was surprisingly stabilized by a less nucleophilic $\mathrm{O}$-py ligand instead of pyridine (py). This compound was then identified as an analogue of the elusive Creigee intermediate as it underwent oxygen insertion into the P-C bond via a mechanism usually observed for BaeyerVilliger oxidations. This oxygen insertion appears to be the first example of a Baeyer-Villiger oxidation involving O-py.

It is generally accepted that organic oxidation reactions are considerably less developed than the corresponding reductions. ${ }^{[1,2]}$ Even though insertion of an oxygen atom into $\mathrm{C}-\mathrm{H}$ or $\mathrm{C}-\mathrm{C}$ bonds are mainly recognized as oxidations, ${ }^{[2]}$ oxygen insertions into $\mathrm{C}-\mathrm{Si}$ (Fleming-Tameo-Kumada oxidations ${ }^{[3]}$ ) and C-B (Brown oxidations ${ }^{[4]}$ ) bonds are also known. With respect to C-P bond oxidation reactions only a handful of examples have been reported and all of them involved phosphorus heterocycles containing ringstrained P-C bonds (Scheme 1). ${ }^{[5]}$ These reactions also required the use of highly reactive $m$-chlorperoxybenzoic acid (mCPBA) or hydrogenperoxide (under elevated temperatures) as oxygen sources. Herein, we wish to report oxygen insertion, under mild conditions, into a P-C bond via a mechanism that resembles Baeyer-Villiger (BV) oxidations. ${ }^{[6]}$ Identification of a key intermediate, that could be considered as a heavy analogue of the elusive Criegee intermediate, ${ }^{[7]}$ was also achieved.

[a] Ms. G. llić, Dr. R. Ganguly, Prof. Dr. D. Vidović* SPMS-Division of Chemistry and Biological Chemistry Nanyang Technological University

21 Nanyang Link

Fax: (+65) 67911961

E-mail:dvidovic@ntu.edu.sg

[b] Prof. Dr. M. Petković

Faculty of Physical Chemistry

University of Belgrade

Studentski Trg 12-16, 11000 Belgrade, Republic of Serbia.

E-mail:milena@ffh.bg.ac.rs

Supporting information for this article is available on the WWW under http://www.chemeurj.org/ or from the author.

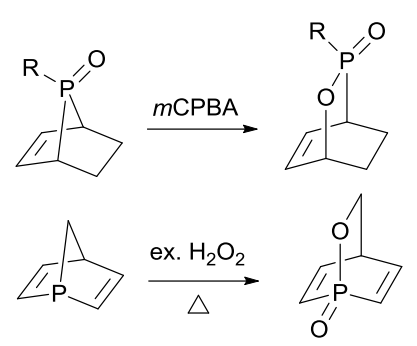

Scheme 1. Typical (but simplified) examples of stained phosphorus heterocycles undergoing $\mathrm{P}-\mathrm{C}$ bond oxidation (see ref. ${ }^{[5]}$ ).

Recent work in our group has been focused on the reactivity of nucleophilic carbone molecules towards various phosphine precursors. ${ }^{[8]}$ The highlight of this work was the synthesis of twocoordinate phosphenium dication $\left[\left(\mathrm{PPh}_{3}\right)_{2} \mathrm{C}-\mathrm{P}-\mathrm{NiPr}_{2}\right]^{2+}\left(\mathbf{1}^{2+}\right.$, Scheme 2a) which was also shown to insert into $\mathrm{O}-\mathrm{H}$ bonds. ${ }^{[8 a, b]}$ These particular results indicated that $\mathbf{1}^{\mathbf{2 +}}$ was quite oxophilic and, thus, we decided to examine its reactivity towards pyridine $\mathrm{N}$-oxide (O-py). As it occurred with the presence of other oxygen donors ${ }^{[8 b]}$ (e.g. $\mathrm{H}_{2} \mathrm{O}, \mathrm{MeOH}$ ), the usual yellow color of $\mathbf{1}^{2+}$ in $\mathrm{DCM}$ instantaneously disappeared upon addition of O-py. Even though the crude reaction mixture contained at least three different products (according to ${ }^{31} \mathrm{P}$ NMR spectroscopy), we managed to crystalize the major product (this product represents about $50 \%$ of all species detected in the initial reaction mixture), identified by $\delta \mathrm{p}$ signals at $\sim 42$ and $24 \mathrm{ppm}$, by layering the reaction mixture with hexane. Single crystal X-ray analysis of this sample revealed that, predictably, we have obtained an oxophosphonium dication $\left(2^{2+}\right.$, Scheme 2a). ${ }^{[9]}$ However, we were somewhat surprised that this dicatacion was stabilized by a molecule of O-py ${ }^{[10]}$ and not pyridine (py) that was produced with oxidation of the phosphorus centre. This observation was quite unusual considering that (i) a similar reaction involving cycling phosphenium cation $\left[\left(\mathrm{CH}_{2}\right)_{2}(\mathrm{~N}\right.$ Dip)2P $]^{+}, \mathbf{4}^{+},\left(\right.$Dip $\left.=2,6-{ }^{-} \mathrm{Pr}_{2}-\mathrm{C}_{6} \mathrm{H}_{4}\right)$ yielded pyridine-stabilized oxophosphenium cation $\mathbf{5}^{+}(\text {Scheme } 2 \mathrm{~b})^{[11]}$ and (ii) py $\left(\mathrm{pK}_{\mathrm{a}}=5.2\right)$ is much more basic than O-py $\left(\mathrm{pK}_{\mathrm{a}}=0.79\right)$. It is plausible that steric factors and/or oxophilic nature of the hypothetically "naked" oxophophonium dication $\left[\left(\mathrm{PPh}_{3}\right)_{2} \mathrm{C}\left(\mathrm{NiPr}_{2}\right) \mathrm{P}=\mathrm{O}\right]^{2+}, \mathbf{2} \mathbf{a}^{2+}$, prevented the coordination of py and/or favoured the coordination of a less sterically demanding and oxygen-containing O-py ligand. Nevertheless, the formation of $\mathbf{2}^{2+}$ is another example that reactivity of dication $\mathbf{1}^{2+}$ towards $\mathrm{O}$-donors is different with respect to its analogous phosphenium monocations. ${ }^{[10 \mathrm{~b}]}$ 


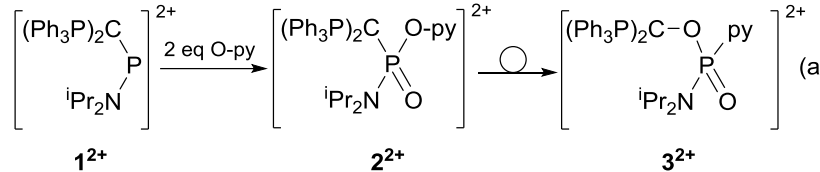

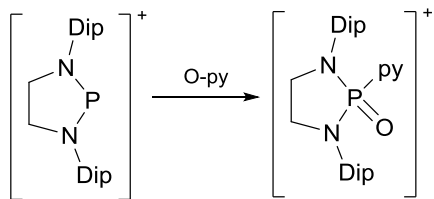

$$
\begin{aligned}
& 4^{+} 5^{+}
\end{aligned}
$$

Scheme 2. Reactivity of (a) phosphenium dication $\mathbf{1}^{2+}$ and (b) monocation $\mathbf{4}^{+}$ towards pyridine $\mathrm{N}$-oxide (O-py) leading to oxygen insertion into a $\mathrm{P}-\mathrm{C}$ bond in the former case.

The molecular structure of $\mathbf{2}^{2+}$ (Figure 1 ) appears to be the first example of cyrstallographically elucidated phosphorus compound that contains an O-py ligand. ${ }^{[12]}$ The $\mathrm{P} 1-\mathrm{O} 2$ dative bond nature was supported by its distance $(1.711(11) \AA)$ and the value for the Wiberg bond index $(0.46)$ obtained by Density Functional Theory (DFT) caluclations. ${ }^{[13]}$ Computational analysis was also performed on the hypothetical O-py-free analogue of $\mathbf{2}^{2+}$ i.e. $\mathbf{2 a}^{2+}$. The removal of the O-py ligand resulted in expected shortening of all the bond distances that the central $P$ forms with the neighbouring atoms. ${ }^{[14]}$ The same observation was also described for $5^{+}$and its base-free analogue. ${ }^{[11]}$ Even though the formal charge of $2^{2+}$ is greater than in the case of $\mathbf{5}^{+}$, it did not translate in vastly different values for the NBO partial charges observed for the central $\mathrm{P}=\mathrm{O}$ fragment of these species. In fact, the $\mathrm{P}=\mathrm{O}$ fragment for $5^{+}$carries a slightly more positive $(+1.332)$ partial charge than the same fragment for $\mathbf{2}^{2+}(+1.257)$. This could be due to electron density overcompensation by the carbone ligand and/or difference in the electronegativity among the atoms in these two molecules that surround the central $P$.

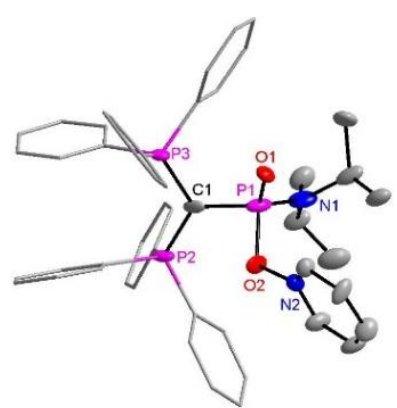

$2^{2+}$

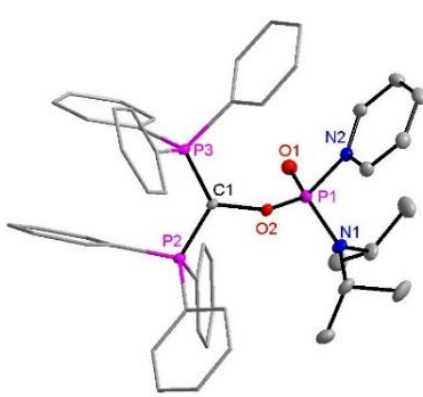

$3^{2+}$
Figure 1. Molecular structures for $\mathbf{2}^{2+}$ and $\mathbf{3}^{2+}$. Apart from the $\mathrm{Ph}$ rings on the carbone substituent all atoms have been drawn at $50 \%$ probability. Hydrogen atoms, solvent molecules and counterions $\left(\mathrm{SbF}_{6}{ }^{-}\right)$for both molecules while the second molecule in the asymmetric unit for only $2^{2+}$ have been omitted for clarity.

It was not immediately evident but $\mathbf{2}^{2+}$ was in fact a key intermediate for the formation of a product that could be detected in the original reaction mixture after few hours. In fact, after isolation of $\mathbf{2}^{\mathbf{2 +}}$ it was possible to follow its conversion to this new product by ${ }^{31} \mathrm{P}$ NMR spectroscopy. Although it takes several days at room temperature, the full conversion could be achieved in about four hours if a DCM solution containing $2^{2+}$ was heated to $50^{\circ} \mathrm{C}$ (Figure 2). Intriguingly, the set of $\delta_{\mathrm{P}}$ signals at $\sim 22$ and $6 \mathrm{ppm}$ assigned to this new product did not show the usual P-P coupling observed in all the compounds that contain a $\mathrm{P}-\mathrm{C}_{\text {(carbone) }}$ bond. ${ }^{\left[{ }^{[8]}\right.}$ This implied the absence of this particular bonding interaction presumably caused by insertion of an atom or a group of atoms into the bond. Indeed, the single crystal X-ray analysis (Figure 1) of this new product revealed that an oxygen atom inserted into the $\mathrm{P} 1-\mathrm{C} 1$ bond of $\mathbf{2}^{2+}$ to form $\mathbf{3}^{2+}$ (Scheme 1a) which also contained a py instead of an O-py ligand.

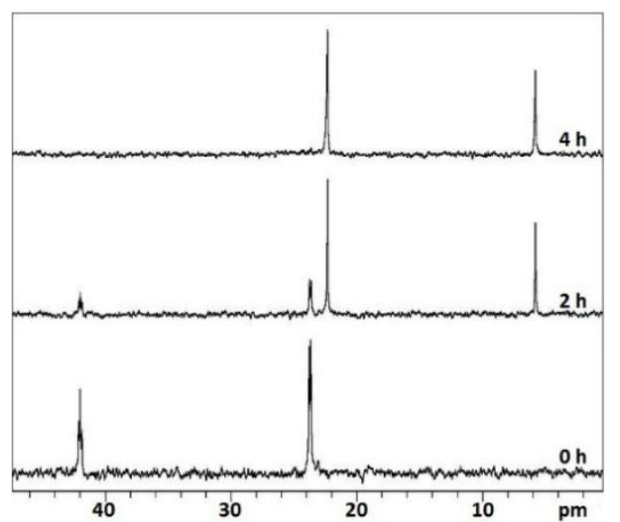

Figure 2. Conversion of $2^{2+}$ into $3^{2+}$ at $50^{\circ} \mathrm{C}$ as followed by ${ }^{31} \mathrm{P}$ NMR spectroscopy.

Computational studies ${ }^{[13]}$ were undertaken to determine the most probable mechanism for this transformation. A transition state $\left(E_{\mathrm{a}}=24 \mathrm{kcal} / \mathrm{mol}\right.$, Figure 3$)$ has been identified suggesting that (i) the mechanism is concerted and (ii) the overall process could be analogous to Baeyer-Villiger (BV) oxidations. ${ }^{[8]}$ The correct mechanism for Beayer-Villiger oxidations, proposed by Criegee ${ }^{[15]}$, was established by the reaction of $\mathrm{O}^{18}$-labelled benzophenone and perbenzoic acid. ${ }^{[16]}$ In the proposed mechanism the peroxy acid attacks the carbonyl group and after intramolecular proton shift it forms the Criegee intermediate (Scheme $3 b$ ). Then, in a quasiconcerted step the initial carbonyl group is re-formed, "one substituent migrates from the carbonyl carbon atom to the partially positive charged oxygen atom" ${ }^{[6 a]}$ and the peroxy acid's $\mathrm{O}-\mathrm{O}$ bond is heterolytically cleaved. ${ }^{[6,16]}$

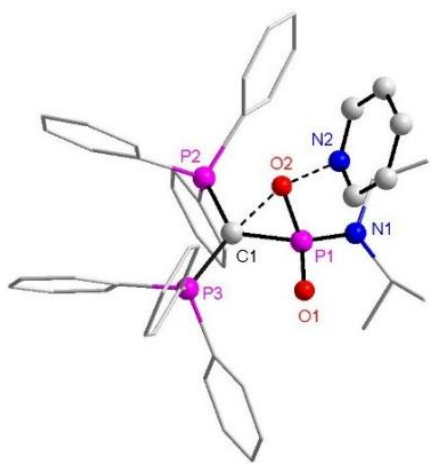

Figure 3. Computationally determined transition state for transformation of $\mathbf{2}^{2+}$ into $3^{2+}$. 
Scheme 3. (a) Established mechanism for the Bayer-Villiger oxydations; (b)

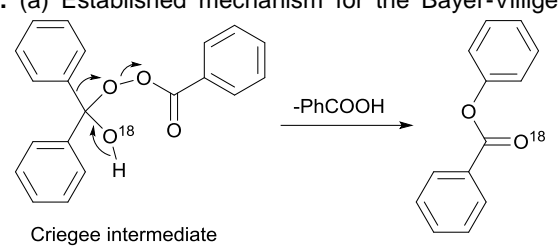

Criegee intermediate

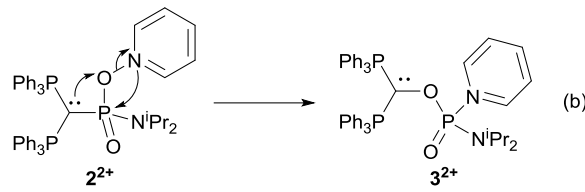

computationally determined mechanism for transformation of $2^{2+}$ to $3^{2+}$.

According to the computational studies a very similar mechanism can be proposed for the formation of $3^{2+}$ (Scheme $3 b$ ). Apart from having a phosphine oxide instead of a carbonyl group, the major differences between the Criegee intermediate and $\mathbf{2}^{2+}$ are protonation of this carbonyl group and the nature of the migratory groups. The absence of the phosphine oxide protonation is not surprising considering the non-protic nature of the O-py oxidant. On the other hand, the electronic (ylide) and steric (see below) nature of the migratory group in $2^{2+}$ seems to be crucial for the overall $\mathrm{P}-\mathrm{C}$ bond oxidation. According to the NBO analysis it is possible to locate a lone pair (confined within a p orbital ${ }^{[14]}$ ) on $\mathrm{C} 1$ which is expectedly a bit delocalized over the surrounding atoms/bonds as its electron population is $1.74 \mathrm{e}$. The absence of this lone pair in the transition state implied its involvement in the formation of the initial $\mathrm{C} 1-\mathrm{O} 2$ bonding interaction. Indeed, according to the NBO analysis this initial interaction is formed by a $p-p$ atomic orbital overlap. In other words, the lone pair on $\mathrm{C} 1$ attacks $\mathrm{O} 2$ resulting in the $\mathrm{C} 1-\mathrm{O} 2$ bond formation and heterolytic cleavage of the O2-N1 bond (Scheme 3b). The initial $\mathrm{C} 1 \rightarrow \mathrm{O} 2$ attack seems possible as $\mathrm{O} 2$ should be more electrophilic when coordinated to the electron deficient $\mathrm{P}$ atom in $\mathbf{2}^{2+}$ with respect to the free molecule. Thus, the presence of a lone pair in $\mathbf{2}^{2+}$, which actually "re-forms" in the final product, ${ }^{[14]}$ seems to be one of the key reasons for the observed facile $\mathrm{O}$ insertion into $\mathrm{P} 1-\mathrm{C} 1$. Furthermore, as required by the BV mechanism the carbone/yilde substituent (the migrating group in this case) is positioned antiperiplanar to the $\mathrm{O}-\mathrm{N}$ bond in the transition state. ${ }^{[6 \mathrm{~b}]}$ It is also noteworthy that the mechanism for the P-C bond oxidation for bicyclic compounds included in Scheme 1 is virtually identical to the BV oxidations of lactones and ketones. ${ }^{[5]}$

In view of the abovementioned experimental and theoretical details the analogy between this P-C bond and the usual BV oxidations is quite evident even though a yilde is the migratory group and the typical $\mathrm{C}=\mathrm{O}$ group has been replaced by a $\mathrm{P}=\mathrm{O}$ group. The relationship between the Creigee intermediate and $\mathbf{2}^{2+}$ might not be as apparent but in both cases the migratory group "attack" and simultaneous $\mathrm{O}-\mathrm{X}(\mathrm{X}=\mathrm{O}$ for $\mathrm{BV} ; \mathrm{X}=\mathrm{N}$ for our case) heterolytic cleavage steps are almost indistinguishable. The only difference, apart from protonation of the carbonyl group, seems to be that in our case the lone pair on $\mathrm{C} 1$ initiates the attack while this is absent in the Creigee intermediate. However, as already mentioned, the presence of a lone pair seems to contribute in lowering the activation energy of the oxygen insertion step. Therefore, compound $\mathbf{2}^{2+}$ could be considered as a heavy analogue of the Criegee-like intermediate ${ }^{[7]}$ while the overall process should be viewed as the first example of an oxidation reaction whose mechanism resembles a BV oxidation in which pyridine $\mathrm{N}$-oxide was used as the oxidant. ${ }^{[6]}$

As previously indicated the formation of $\mathbf{2}^{2+}$ was somewhat surprising considering that a less basic $\mathrm{O}$-py ligand stabilized the oxophosphonium dication even though more basic py was present in the solution. We attributed this observation to steric factors and/or oxophilic nature of $\mathbf{2 a}^{2+}$ as O-py appeared to be less sterically encumbered than py and it contains an O-donor atom. ${ }^{[17]}$ Thus, we wanted to determine whether the steric strain of $2^{2+}$ played an important role in the overall transformation of $2^{2+}$ to $3^{2+}$. In fact, according to the solid state analysis of these two dications the O1-P1-N1 angle increased from $112.6(7)^{\circ}$ for $\mathbf{2}^{2+}$ to $118.6(1)^{\circ}$ for $3^{2+}$ suggesting alleviation of the steric strain after the oxygen insertion. This is further supported by the fact that (i) the P1-O1 (1.456(10) (1.454(10)) and 1.451(2) $\AA$ for $\mathbf{2}^{2+}$ and $3^{2+}$, respectively) and P1-N1 (1.617(16) (1.54(2)) and 1.611(3) $\AA$ for $\mathbf{2}^{2+}$ and $3^{2+}$, respectively) bond lengths, (ii) the orbital makeup (NBO analysis) of these bonds (iii) the electronic population of the $\mathrm{C} 1$ lone pair (1.70 and $1.71 e$ for $2^{2+}$ and $3^{2+}$, respectively) were virtually unchanged during the oxidation. ${ }^{[14]}$ This evidence would suggest that electronic effects of the ligands surrounding the central $P$ were highly unlikely responsible for the observed O1-P1-N1 angle widening. Thus, these observations indicated that the insertion of an $\mathrm{O}$ atom into $\mathrm{P} 1-\mathrm{C} 1$ bond of $\mathbf{2}^{2+}$ has alleviated some of the steric strain presumably because the bulky carbone ligand has been "pushed away" from the central P. To quantify the energy released by diluting the steric congestion the carbone coordinates from the optimized structures for $\mathbf{2}^{2+}$ and $\mathbf{3}^{\mathbf{2 +}}$ have been extracted and their respective energy computed without any further optimizations. The energy difference of $7.0 \mathrm{kcal} / \mathrm{mol}$ between the two fixed carbone structures has been obtained. If we assume that the carbone ligand in $\mathbf{2}^{2+}$ has been sterically strained by this amount of energy three conclusions could be formulated. The first, the steric strain does not have any effect on the outcome of the overall oxidation reaction considering it is exergonic by $31.8 \mathrm{kcal} / \mathrm{mol}$. The second, this steric strain appears to considerably increase the reaction rate because adding $7.0 \mathrm{kcal} / \mathrm{mol}$ to the $\mathrm{E}_{\mathrm{a}}$ would increase the activation temperature by about $25 \%$. In other words, the reaction would not have happened at room temperature $\left(20^{\circ} \mathrm{C}\right.$ or $\left.293 \mathrm{~K}\right)$ and heating to about $90^{\circ} \mathrm{C}$ (or $366 \mathrm{~K}$ ) would have been required. Despite the fact there is a limited amount of information regarding the quantification of steric strain on reaction rates, many example exist in which various steric factors were identified as the main reason in enhancing the corresponding reaction rates. ${ }^{[18]}$ Lastly, this steric strain could be in part responsible for preventing the coordination of a more nucleophilic but more sterically demanding py ligand to $2 \mathrm{a}^{2+}$ in favour of O-py to form $\mathbf{2}^{2+}$. However, the established oxophilicity of these cationic species might play a role in favouring the coordination of the oxygen containing ligand.

In conclusion, oxygen insertion into a P-C bond (using mild reaction conditions) has been demonstrated. According to computational analysis the mechanism for this insertion resembled Baeyer-Villiger (BV) oxidations. The key intermediate has also been identified which could be considered as a Criegee-like intermediate which is usually not observed in BV insertions. Lastly, the steric strain in this intermediate greatly lowered the activation energy but it did not influence the final outcome of the process.

\section{Acknowledgements}


We would like to thank $A^{*}$ STAR (DV, \# 1220703062) and the Ministry of Education, Science, and Technological Development of the Republic of Serbia within the framework of the project 172040 (MP) for financial support. Computational analysis were performed on the PARADOX cluster at the Scientific Computing Laboratory of the Institute of Physics Belgrade, supported in part by the Ministry of Education, Science, and Technological Development of the Republic of Serbia under project No. ON171017 (MP).

\section{Keywords: P-C bond oxidation - Baeyer-Villiger oxidation •} Creigee intermediate $\cdot$ phosphenium dication $\cdot$ main-group chemistry

[1] For reductions/hydrogenations, see: a) M. Gouygou, P. Kalck, M. Urrutigoity in Comprehensive Inorganic Chemistry II (Eds.: J. Reedijk, K. Poeppelmeier), Elsevier Ltd., 2013, pp. 223-247; b) J. W. Burton in Comprehensive Organic Synthesis, Vol. 8 (Eds.: P. Knochel, G. A. Molander), Elsevier Ltd., 2014, pp. 446-478; c) D. Ager in Comprehensive Organic Synthesis, Vol. 8 (Eds.: P. Knochel, G. A. Molander), Elsevier Ltd. 2014, pp. 605-631; d) D. W. Stephan, G. Erker, Angew. Chem. Int. Ed 2015, 54, 6400; e) P. J. Chirik, Acc. Chem. Res. 2015, 48, 1687; f) T. Zell, D. Milstein, Acc. Chem. Res. 2015, 48, 1979; g) S. Chakraborty, P. Bhattacharya, H. Dai, H. Guan, Acc. Chem. Res. 2015, 48, 1995.

[2] For oxidations, see: a) A. E. Shilov, G. B. Shul'pin, Chem. Rev. 1997, 97, 2879 ; b) P. P.-Y. Chen, R. B.-G. Yang, J. C.-M. Lee, S. I. Chan, PNAS 2007, 104, 14570; c) T. Newhouse, P. S. Baran, Angew. Chem. Int. Ed. 2011, 50, 3362

[3] See, for example: a) K. Tamao, N. Ishida, M. Kumada, J. Org. Chem. 1983, 48, 2120; b) K. Tamao, N. Ishida, T. Tanaka, M. Kumada, Organometallics 1983, 2, 1694; c) I. Fleming, R. Henning, H. Plaut, Chem. Commun. 1984 29; d) I. Fleming, P. E. J. Sanderson, Tetrahedron Lett. 1987, 28, 4229.

[4] See, for example: a) H. C. Brown, G. Zweifel, J. Am. Chem. Soc. 1959, 81, 247 ; b) H. C. Brown, S. K. Gupta, J. Am. Chem. Soc. 1972, 94, 4370

[5] a) Y. Kashman, O. Awerbouch, Tetrahedron 1975, 31, 45; b) L. D. Quin J. C. Kisalus, K. A. Mesch, J. Org. Chem. 1983, 48, 4466; c) L. D. Quin, B. G. Marsi, J. Am. Chem. Soc. 1985, 107, 3389; d) L. D. Quin, J. Szewczyk, K. M. Szewczyk, A. T. McPhail, J. Org. Chem. 1986, 51, 3341; e) L. D. Quin, X.-P. Wu, Heteroatom Chem. 1991, 2, 99; f) L. D. Quin, XP. Wu, Heteroatom Chem. 1991, 2, 359; g) V. Mouriès, F. Mercier, L. Ricard, F. Mathey, Eur. J. Org. Chem. 1998, 2683; h) S. Jankowski, G. Keglevich, T. Nonas, H. Forintos, M Główka, J. Rudziński, Tetrahedron 2004, 60, 2789; i) S. Jankowski, K. Huben, Curr. Org. Chem. 2006, 10, 79 j) H. Wang, C. Li, D. Geng, H. Chen, Z. Duan, F. Mathey, Chem. Eur. J. 2010, 16, 10659

[6] For BA oxidations, see: a) M. Renz, B. Meunier, Eur. J. Org. Chem. 1999 737; b) G.-J. ten Brink, I. W. C. E. Arends, R. A. Sheldon, Chem. Rev. 2004, 104, 4105; c) C. Bolm, C. Palazzi, O. Beckmann in Transition Metals for Organic Synthesis, Vol. 2 (Eds.: M. Beller and C. Bolm), Wiley-VCH
Weinheim, 2004, pp. 267-274; d) M. Uyanik, K. Ishihara, ACS Catal. 2013, 3, 513.

[7] a) C. A. Taatjes, G. Meloni, T. M. Selby, A. J. Trevitt, D. L. Osborn, C. J. Percival, D. E. Shallcross, J. Am. Chem. Soc. 2008, 130, 11883; b) M. Nakajima, Y. Endo, J. Chem. Phys. 2013, 139, 101103.

[8] a) M. Q. Y. Tay, Y. Lu, R. Ganguly, D. Vidović, Angew. Chem. Int. Ed. 2013, 52, 3132.; b) M. Q. Y. Tay, Y. Lu, R. Ganguly, D. Vidović, Chem. Eur. J. 2014, 20,6628; c) Y. K. Loh, C. Gurnani, R. Ganguly, D. Vidović, Inorg. Chem. 2015, 57, 3087; d) N. Đorđević, M. Q. Y. Tay, S. Muthaiah, R. Ganguly, D. Dimić, D. Vidović, Inorg. Chem. 2015, 54, 4180; e) C. Gurani, N. Đorđević, S. Muthaiah, D. Dimić, R. Ganguly, M. Petković, D. Vidović, Chem. Commun. 2015, 51, 10762; f) M. Q. Y. Tay, Y. Lu, R. Ganguly, G. Frison, L. Richard, D. Vidović, D. Charmichael, Phosphorus, Sulfur Silicon Relat. Elem. 2015, 190, 785; g) M. Q. Y. Tay, G. Ilić, U. Werner-Zwanziger, Y. Lu, R. Ganguly, L. Richard, G. Frison, D. Carmichael, D. Vidović, Organomtallics, 2015, Accepted.

[9] The asymmetric unit for $\mathbf{2}^{2+}$ contains two independent molecules.

[10] Regardless of the $1^{2+}$ :O-py stoichiometry used (e.g. 1:1 or 1:2) we always identified the presence of $\mathbf{2}^{2+}$

[11] A. D. Hendsbee, N. A. Giffin, Y. Zhang, C. C. Pye, J. D. Masuda, Angew Chem. Int. Ed. 2012, 51, 10836.

[12] Searching the Cambridge Structure Database for any structures containing a P-O-py fragment yielded no hits (31/07/2015).

[13] All computational studies for this work have been performed at the B3LYP level using the 6-31G(d) basis set.

[14] See the Supplementary Information.

[15] R. Criegee, Justus Liebigs Ann. Chem. 1948, 560, 127.

[16] W. v. E. Doering, E. Dorfman, J. Am. Chem. Soc. 1953, 75, 5595.

[17] We attempted exchanging the O-py lingad in $\mathbf{2}^{2+}$ with numerous Lewis based. In most cases we obtained a complex mixture of unidentified products (according to ${ }^{31} \mathrm{P}$ NMR spectroscopy). When $\mathrm{Cy}_{3} \mathrm{P}$ was added to this dication we managed to identify small quantities of $\mathrm{Cy}_{3} \mathrm{P}=\mathrm{O}$ by ${ }^{13} \mathrm{P}$ NMR spectroscopy and Mass spectrometry.

[18] See, for example: a) L. Canovese, F. Visentin, G. Chessa, P. Uguagliati, G. Bandoli, Organometallics 2000, 19, 1461; b) B. Neuwald, L. Falivene, L. Caporaso, L. Cavallo, S. Mecking, Chem.-Eur. J. 2013, 19, 17773.

Received: ((will be filled in by the editorial staff)) Revised: ((will be filled in by the editorial staff)) Published online: ((will be filled in by the editorial staff)) 


\section{Entry for the Table of Contents}

Layout 2:

\section{COMMUNICATION}

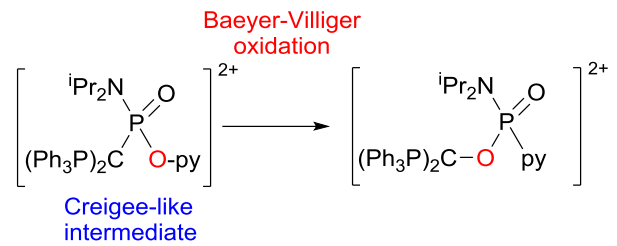

P-C bond oxidation

Gordana Ilić, Rakesh Gaguly, Milena Petković*, Dragoslav Vidović*

The reactivity of phosphenium dication $\left[\left(\mathrm{Ph}_{3} \mathrm{P}\right)_{2} \mathrm{C}-\mathrm{P}-\mathrm{NiPr}_{2}\right]^{2+}$ towards pyridine $\mathrm{N}$-oxide (O-py) has been investigated. The resulting oxophosphonium dication $\left[\left(\mathrm{Ph}_{3} \mathrm{P}\right)_{2} \mathrm{C}\left(\mathrm{NiPr}_{2}\right) \mathrm{P}(\mathrm{O})(\mathrm{O}-\mathrm{py})\right]^{2+}$ was surprisingly stabilized by a less nucleophilic O-py ligand instead of pyridine (py). This compound was then identified as an analogue of the elusive Creigee intermediate as it underwent oxygen insertion into the P-C bond via a mechanism usually observed for Baeyer-Villiger oxidations 